\title{
RESEARCH OF HEAT AND MASS TRANSFER PROCESSES IN THE NODES OF FREE-FLOW MICRO-HPP WITH THE USE OF 3D TECHNOLOGY
}

\author{
Stanislav Yankovsky ${ }^{1, *}$, German Kulupanov ${ }^{1}$, and Vladimir Andriyashchenko ${ }^{1}$ \\ ${ }^{1}$ Tomsk Polytechnic University, 634050, Lenin Avenue 30, Tomsk, Russia
}

\begin{abstract}
In the article the analysis of existing micro-hydro turbines. Created 3D experimental model. Designed and developed an experimental stand for testing micro-turbine. Investigated options for generators on permanent magnets, selected the optimum scheme and developed a prototype three phase generator with permanent magnets.
\end{abstract}

\section{Introduction}

Production of electrical energy is the basis of life for all industries. The largest share of electricity generation falls on the use of fossil fuels. Trend of continuous growth in electricity consumption and heavy pollution forces international community to muse upon not only traditional energy sources, but also to look closer at renewable energy sources such as wind, solar, biomass and small-scale energy using water.

Small-scale energy - is the most cost-effective solution to energy problems today. According to specialists, technical hydropower potential of small Russian rivers is 170 billion kilowatt-hours per year, which allows building small hydropower plants with total installed capacity of over $40 \mathrm{GW}$ [1]. There are more than 200 hydraulic structures in Europe [2]. The use of mini-hydropower plants in these countries provides an additional amount of electricity without major capital investment.

It follows from the foregoing, that creation of free-flow micro-HPPs is an urgent task. It is necessary to develop and design a prototype of operating autonomous free-flow low power hydro turbine, using modern 3D-printing technology, widely implemented in the modern world.

\section{Research and development}

Research of sci-tech literature, which describes the existing installations, both in Russia and Europe was conducted to create a turbine model. Analysis of existing prototypes on the following parameters was conducted: the number of revolutions at low flow rates, size, ease of design, reliability and behavior of the water flow.

*Corresponding author: jankovsky@,tpu.ru 


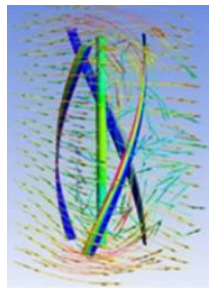

Fig. 1. lines of flux in helical blades turbine [3].

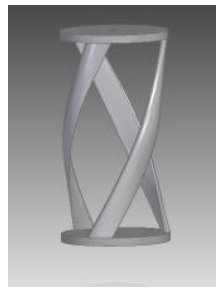

Fig. 2. 3D-model of the turbine.

It can concluded analyzing behavior of 3D-model of the turbine (figure 1) with twirled (helicoid) blades, that this model has advantages over other types:

- High speed of uniform rotation at a relatively slow liquid flow (low pressure liquid);

- High efficiency;

- Absence of torque fluctuations;

- Absence of visible signs of cavitation in water at a high speed;

- Self-start in slow waters or wind.

Results of the analysis showed that the model of three-blade helicoid turbine invented by A.M. Gorlov best suites the declared parameters. [5]

Standard profile NACA 4418 is taken as an profile of the blades [5].

Models of blades and two bases for the turbine were designed and visualized with the use of Solid Edge program (figure 2).

Prototype was obtained with the use of 3D-printing technology. Experimental hydraulic test setup was constructed for tests and study of heat and mass transfer processes in the mobile nodes of micro-turbine and subsequent upgrades. This setup allows comparing data of mathematical modeling with natural tests.

Hydraulic test setup allows simulating processes of water flow in rivers by the use of hydraulic pumps with frequency regulation. Created conditions are as realistic as possible (there are portions of fluid flow similar to the laminar, which are used for tests) (figure 4). This stand is applicable not only for scientific purposes, but also for training undergraduates in order to improve their skills. [6-8]

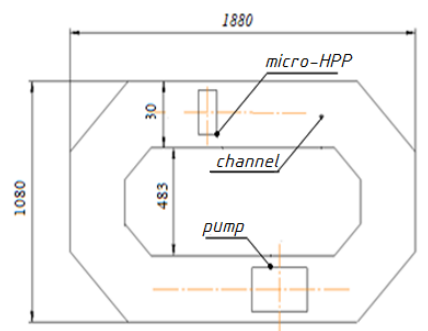

Fig. 3. Hydraulic test setup.

Compact generator is required to convert kinetic energy of the turbine into electrical. It allows to generate electricity capable of charging mobile devices and computers. During the study of generators design, it was found out that output is reduced to zero 3 times per revolution in single-phase generator, while induction generator has a complex and bulky design concept. Three-phase generator with permanent magnets has an optimum design, is easy to operate and manufacture and has small size with good output power. Based on the foregoing, creation of the prototype was based on the three-phase generator design. Modeling and design of the generator was performed in the Solid Edge program (figure 5). Elements of experimental model were created using the 3D-printer. Currently, components are being assembled. 
Created model of hydro turbine is in stage of testing. Generator is in assembly stage.

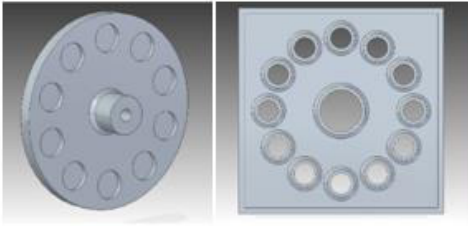

a)

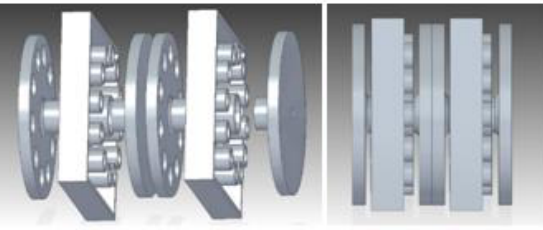

b) c)

Fig. 4. 3D-model of the generator, a) component parts; b) exploded view; c) assembly of the model.

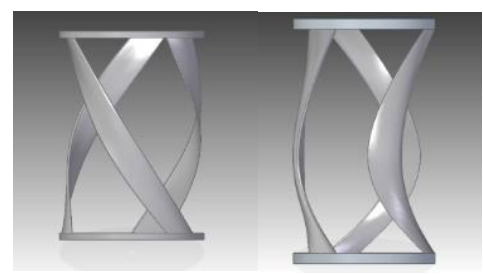

Fig. 5. Possible blades modifications.

\section{Conclusion}

Unique hydraulic test setup for the tests of micro-turbines in the water flow was created;

Installation of hydro turbine was designed and manufactured;

Three-phase generator was designed.

Main research areas: necessity to improve the blades (figure 6), improve performance of micro hydro turbine and synchronize with the developed generator. Explore the most optimal modes of micro HPP operation. Explore processes of heat and mass transfer in mobile nodes of hydro unit; compare simulation results with real experiments.

\section{Acknowledgments}

Work is performed within the program of increasing competitiveness of TPU.

\section{References}

1. V.I. Dobrohotov, V.M. Kargiev, A.B. Belov, D.S. Strebkov, A.K. Sokolsky, M.B. Sachs, V.V. Afyan. Renew. En. (2005)

2. S. Yankovsky, Basics Thermal Energy Technology (Publishing house TPU, Tomsk, 2010)

3. Taco Anton Niet, Modelling Renewable Energy at Race Rocks (University of Victoria, 1988)

4. V.V. Ermolaev, N.N. Gudkov, A.N. Babiev, O.N. Petrova O.N, S.A. Galaev, A.I. Kirillov, E.M. Smirnov, Therm. Eng. 4 (2007)

5. A. M. Gorlov, A. N. Gorban, V. M. Silantyev, J. En. Res. Tech. (2001)

6. K. B. Larionov, S.V. Lavrinenko, V.E. Gubin, G.A. Kitaev, Procedia - Soc. and Beh. Sc. $206(2015)$

7. S. V. Lavrinenko et. al., Procedia - Soc. and Beh. Sc. 206 (2015)

8. S. A. Yankovsky et. al., MATEC Web Conf. 37 (2015) 